\title{
Psammaplins from the Sponge Pseudoceratina purpurea: Inhibition of Both Histone Deacetylase and DNA Methyltransferase
}

\author{
Ivette C. Piña ${ }^{\dagger, a}$ Jeffrey T. Gautschi ${ }^{\dagger}$ Gui-Yang-Sheng Wang, ${ }^{\dagger}$ Miranda L. Sanders, ${ }^{\dagger}$ \\ Francis J. Schmitz, ${ }^{\ddagger}$ Dennis France, ${ }^{\S}$ Susan Cornell-Kennon, ${ }^{\S}$ Lidia C. Sambucetti, ${ }^{\S}$ Stacy \\ W. Remiszewski ${ }^{\S}$ Larry B. Perez, ${ }^{\S}$ Kenneth W. Bair, ${ }^{\S}$ and Phillip Crews ${ }^{\dagger}$ \\ ${ }^{\dagger}$ Department of Chemistry and Biochemistry \& Institute of Marine Sciences, University of \\ California, Santa Cruz, CA 95064 \\ ${ }^{*}$ Department of Chemistry and Biochemistry, University of Oklahoma, Norman, OK \\ 73019 \\ ${ }^{\S}$ Oncology Research Program, Preclinical Research, Novartis Institute for Biomedical \\ Research, Summit, NJ 07901
}

\section{Supporting Information}

Spectrum S1. ${ }^{13} \mathrm{C}$ NMR of 9 at $125 \mathrm{MHz}$ in $\mathrm{CD}_{3} \mathrm{OD}$. Spectrum S2. ${ }^{1} \mathrm{H}$ NMR of 9 at $500 \mathrm{MHz}$ in $\mathrm{CD}_{3} \mathrm{OD}$. Spectrum S3. ${ }^{13} \mathrm{C}$ NMR of $\mathbf{1 0}$ at $125 \mathrm{MHz}$ in $\mathrm{CD}_{3} \mathrm{OD}$. Spectrum S4. ${ }^{1} \mathrm{H}$ NMR of $\mathbf{1 0}$ at $500 \mathrm{MHz}$ in $\mathrm{CD}_{3} \mathrm{OD}$. Spectrum S5. HRFAB ${ }^{+}$MS of 11. Spectrum S6. HMBC of 11 at $500 \mathrm{MHz}$ in $\mathrm{DMSOd}_{6}$. Spectrum S7. ${ }^{13} \mathrm{C}$ NMR of $\mathbf{1 2}$ at $500 \mathrm{MHz}$ in $\mathrm{CD}_{3} \mathrm{OD}$. Spectrum S8. ${ }^{1} \mathrm{H}$ NMR of $\mathbf{1 3}$ at $500 \mathrm{MHz}$ in $\mathrm{CD}_{3} \mathrm{OD}$. Spectrum S9. ${ }^{13} \mathrm{C}$ NMR of $\mathbf{1 3}$ at $500 \mathrm{MHz}$ in $\mathrm{CD}_{3} \mathrm{OD}$. Spectrum S10. ${ }^{1} \mathrm{H}$ NMR of $\mathbf{1 4}$ at $500 \mathrm{MHz}$ in $\mathrm{CD}_{3} \mathrm{OD}$. Spectrum S11. ${ }^{13} \mathrm{C}$ NMR of 14 at $500 \mathrm{MHz}$ in $\mathrm{CD}_{3} \mathrm{OD}$. Spectrum S12. Expansion of gHMQC of 14 at $500 \mathrm{MHz}$ in $\mathrm{CD}_{3} \mathrm{OD}$.

a Permanent affiliation: Centro de Química Orgánica, Escuela de Química, Facultad de Ciencias, Universidad Central de Venezuela, Apartado 47102, Caracas 1020AVenezuela.

To whom correspondence should be addressed. Tel: (831) 459-2603, Fax: (831) 4592935. E-mail: phil@chemistry.ucsc.edu. 


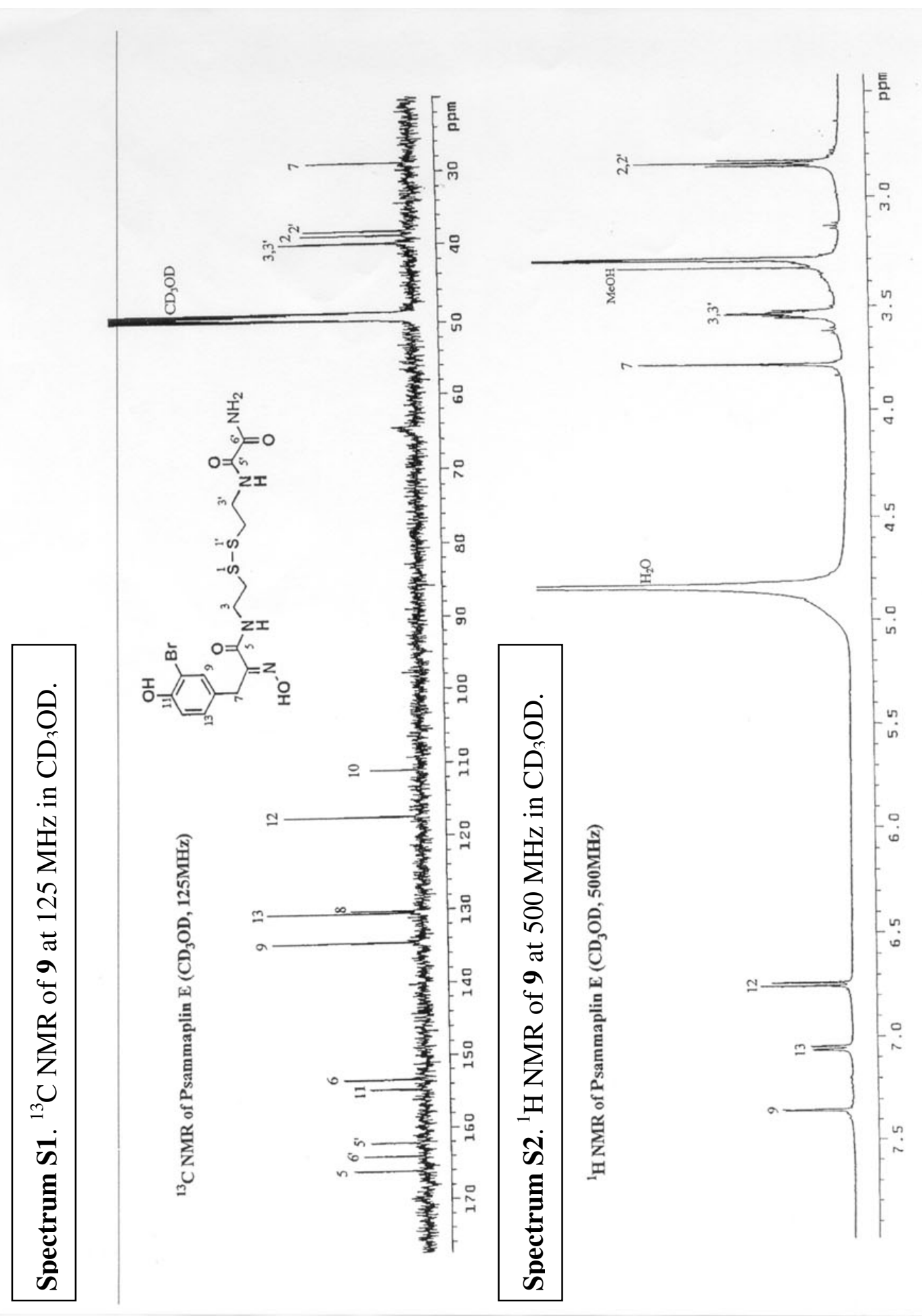




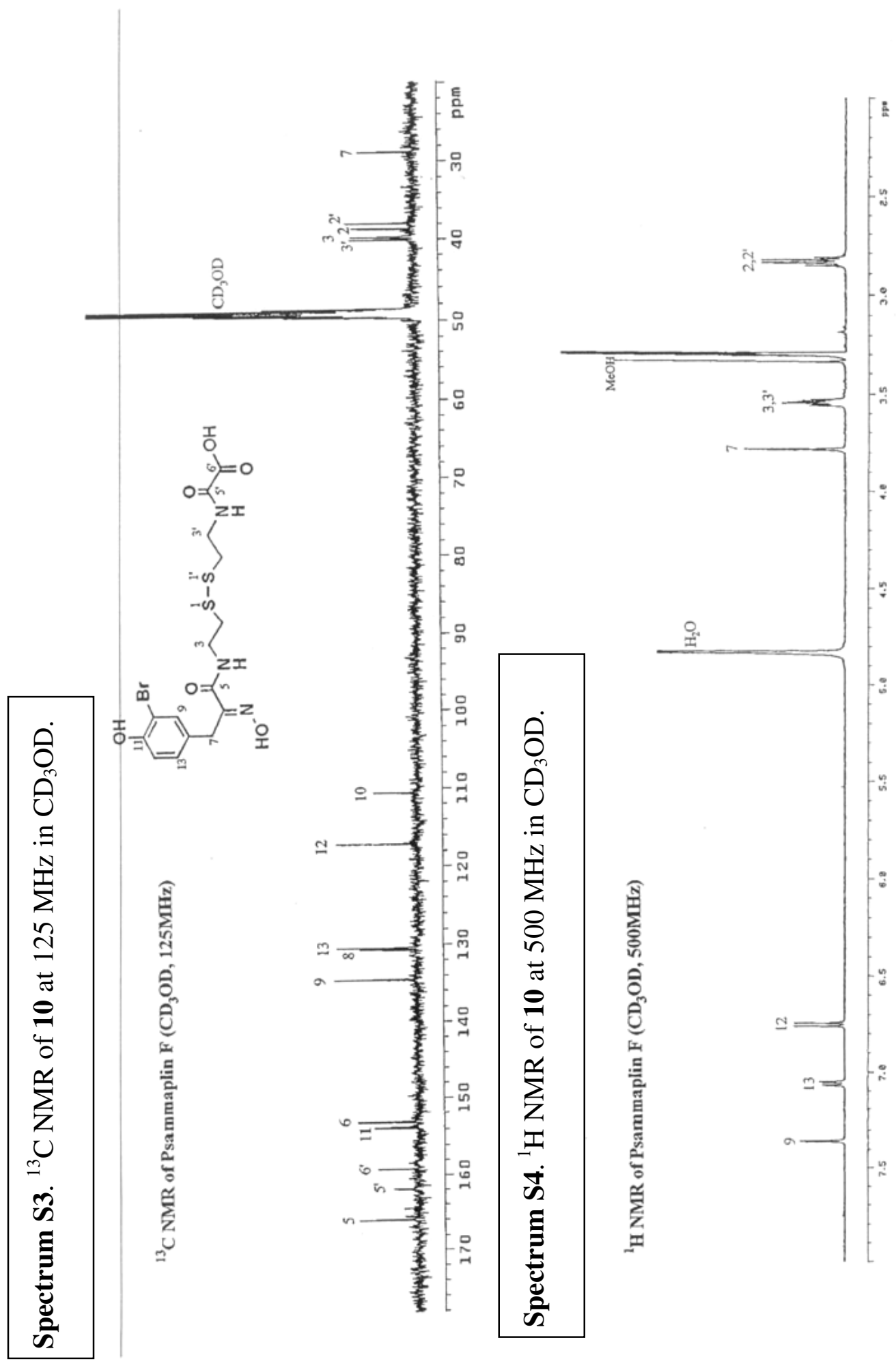




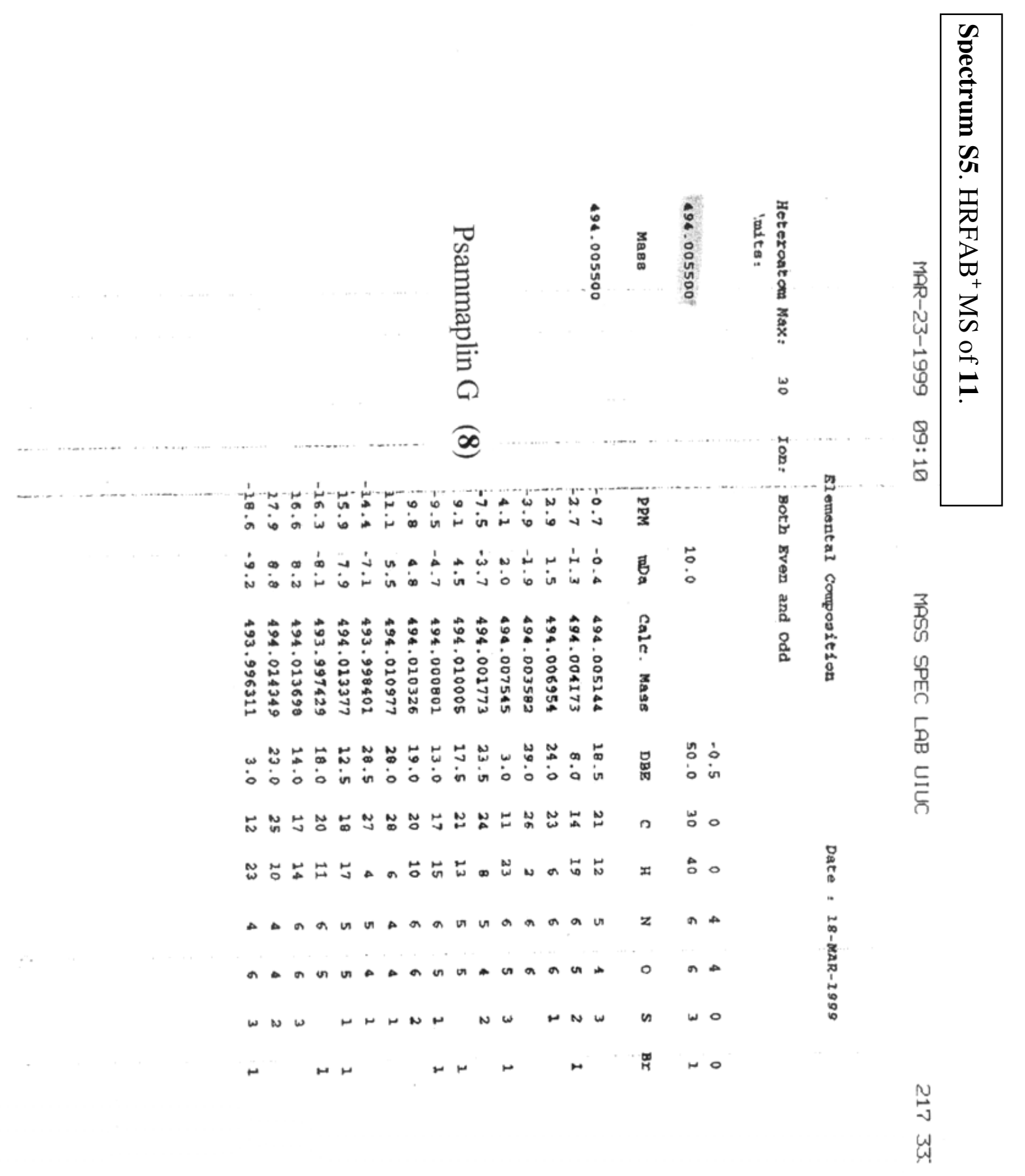




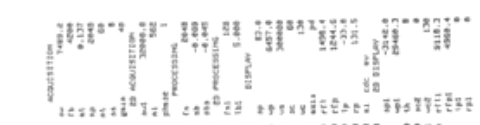

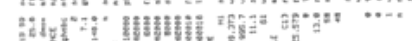

ti

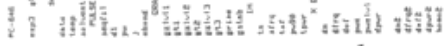

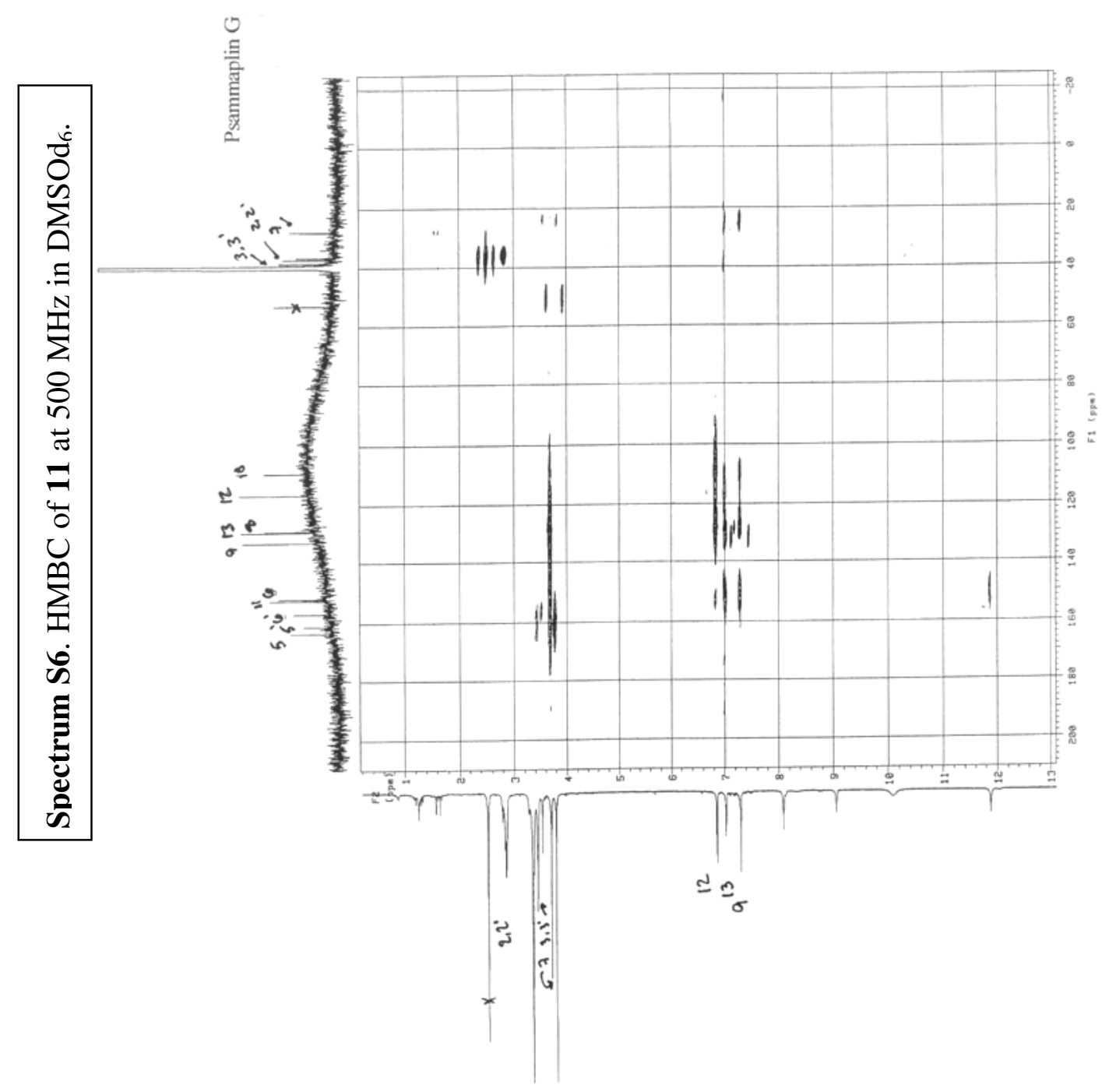




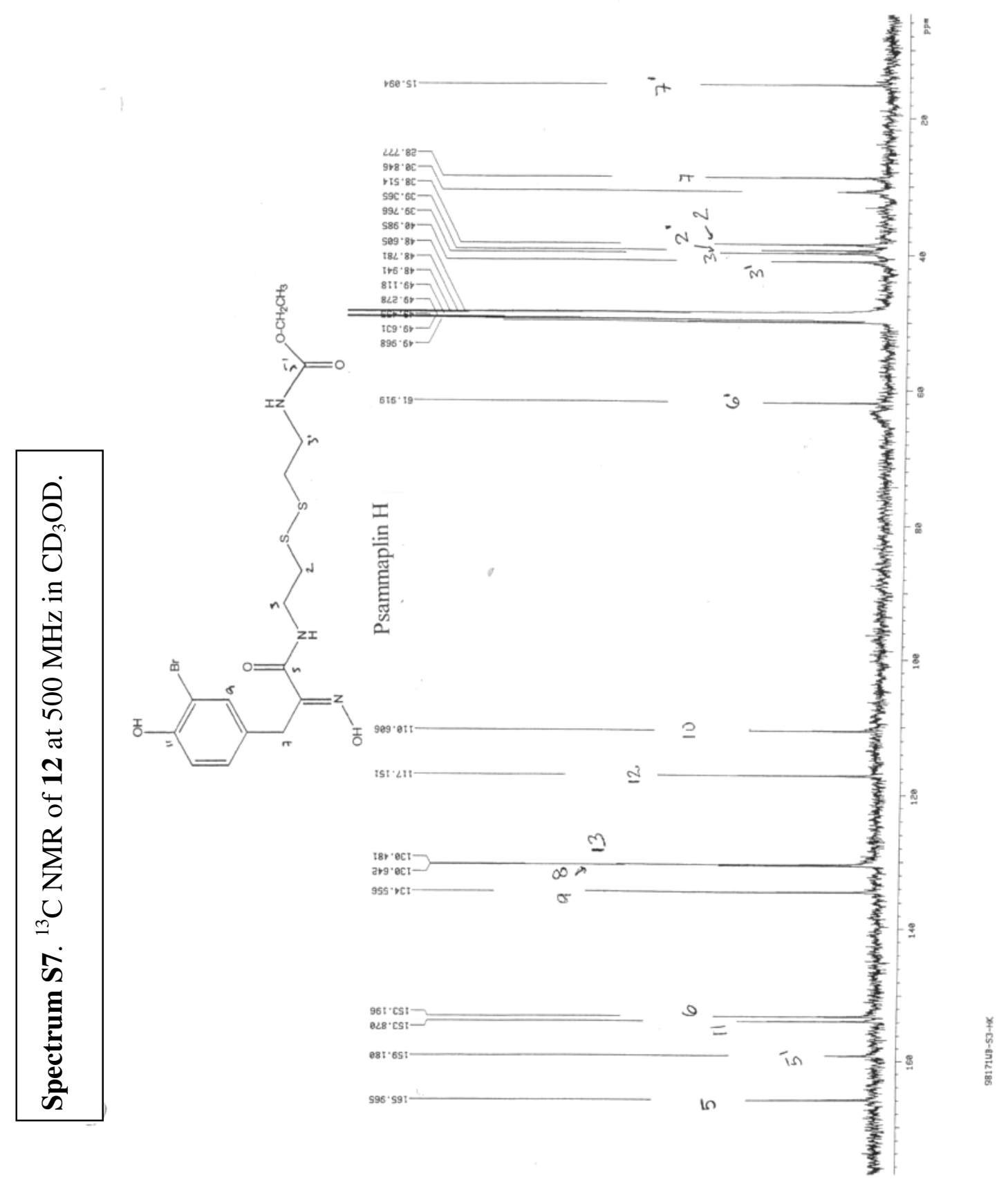



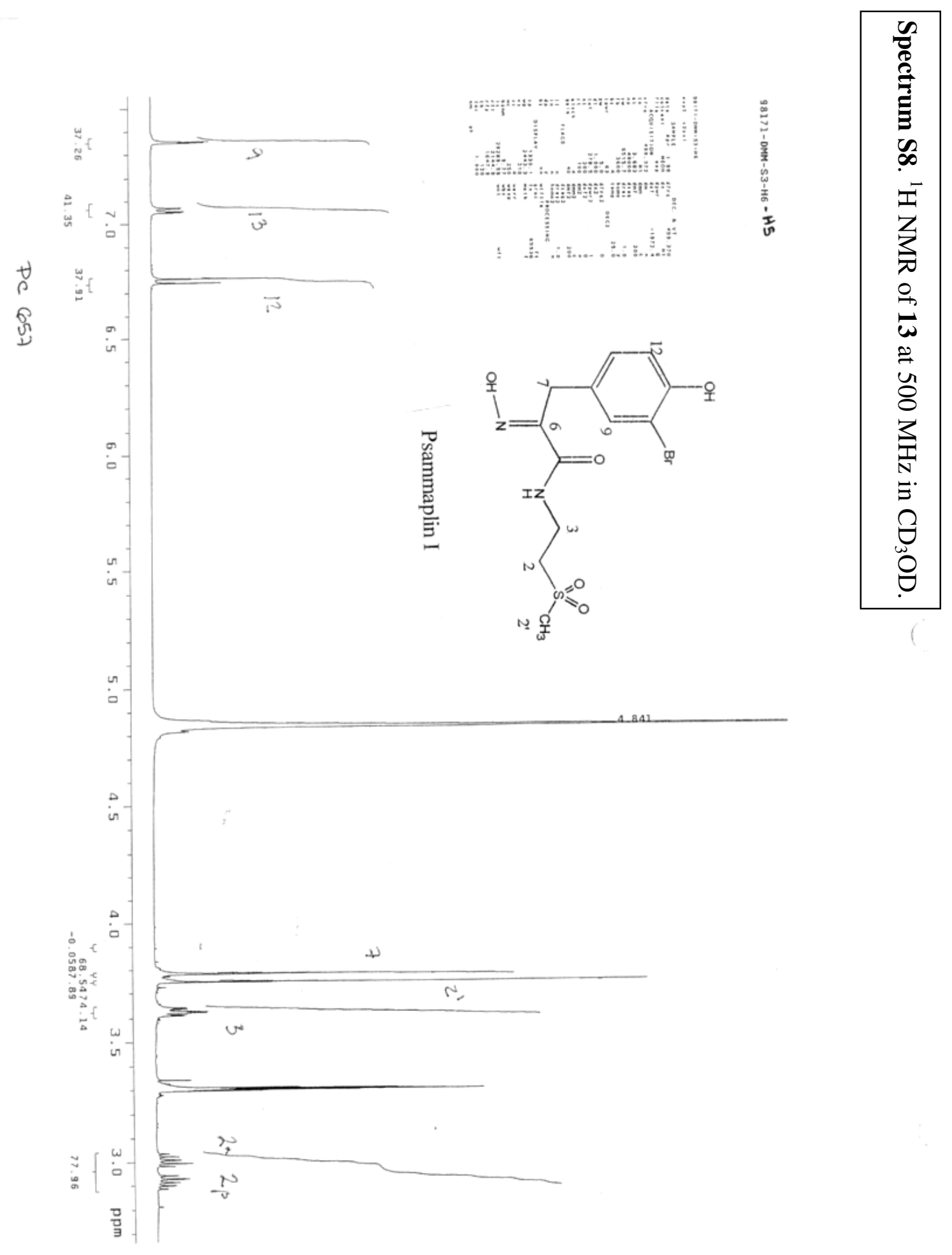


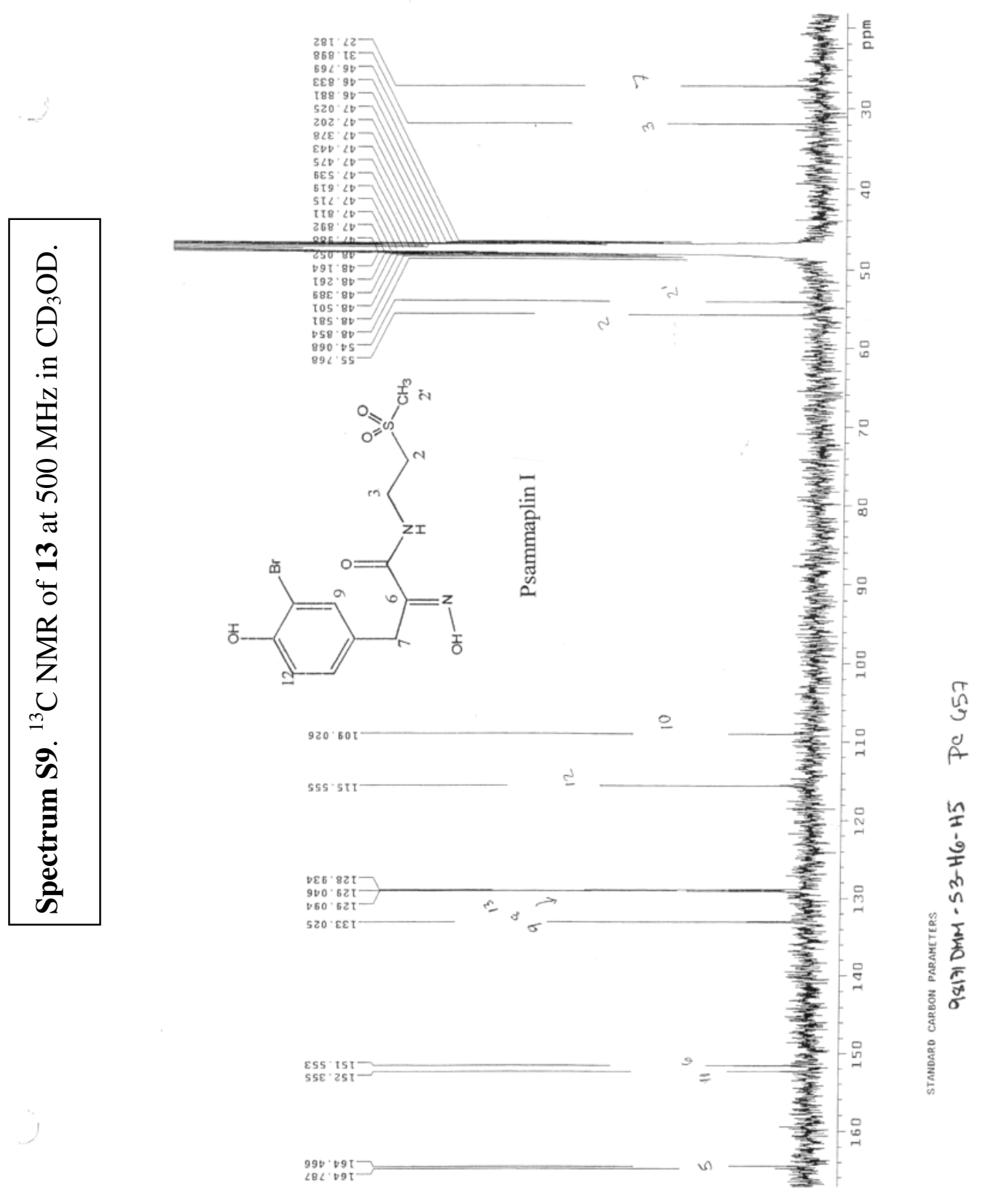




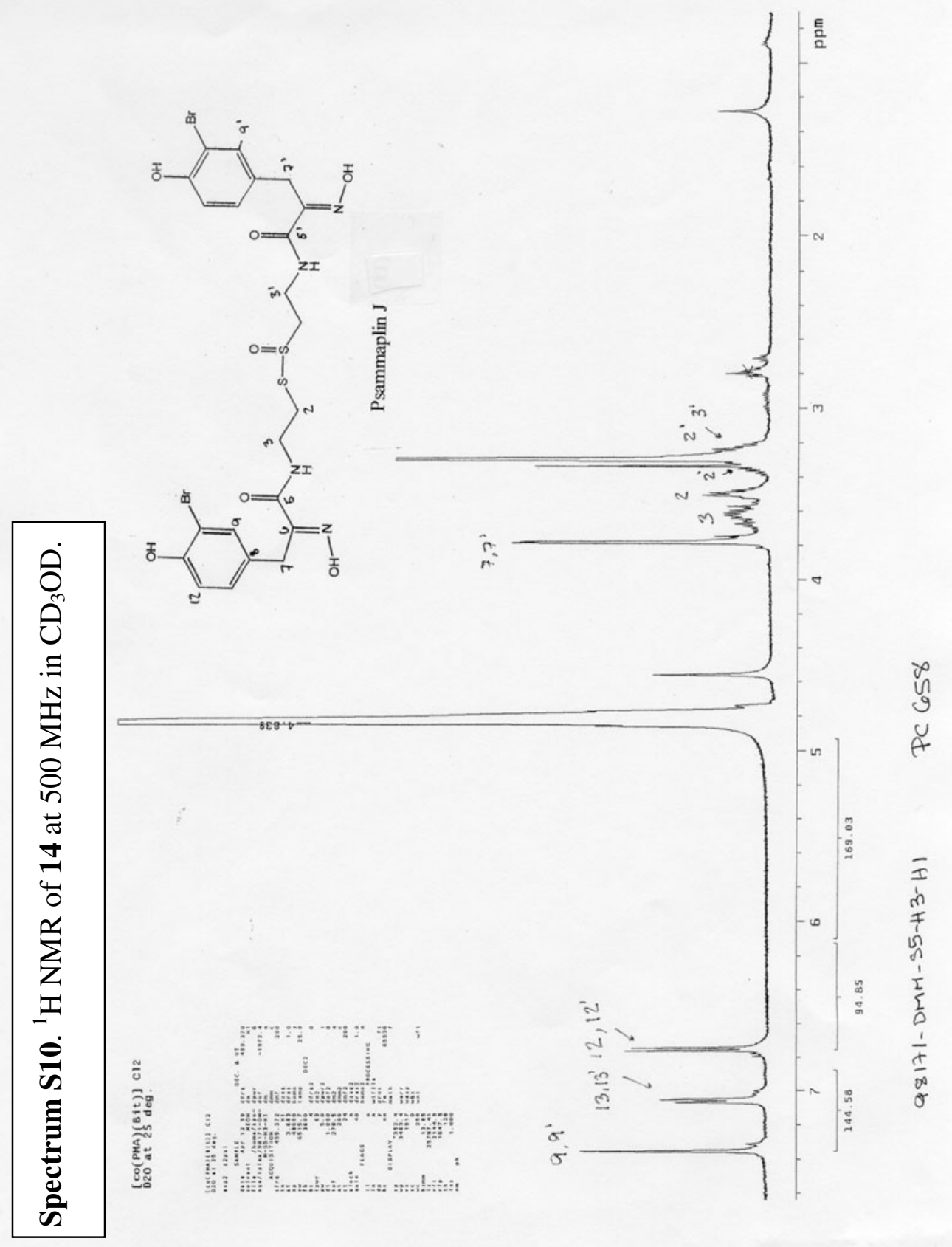




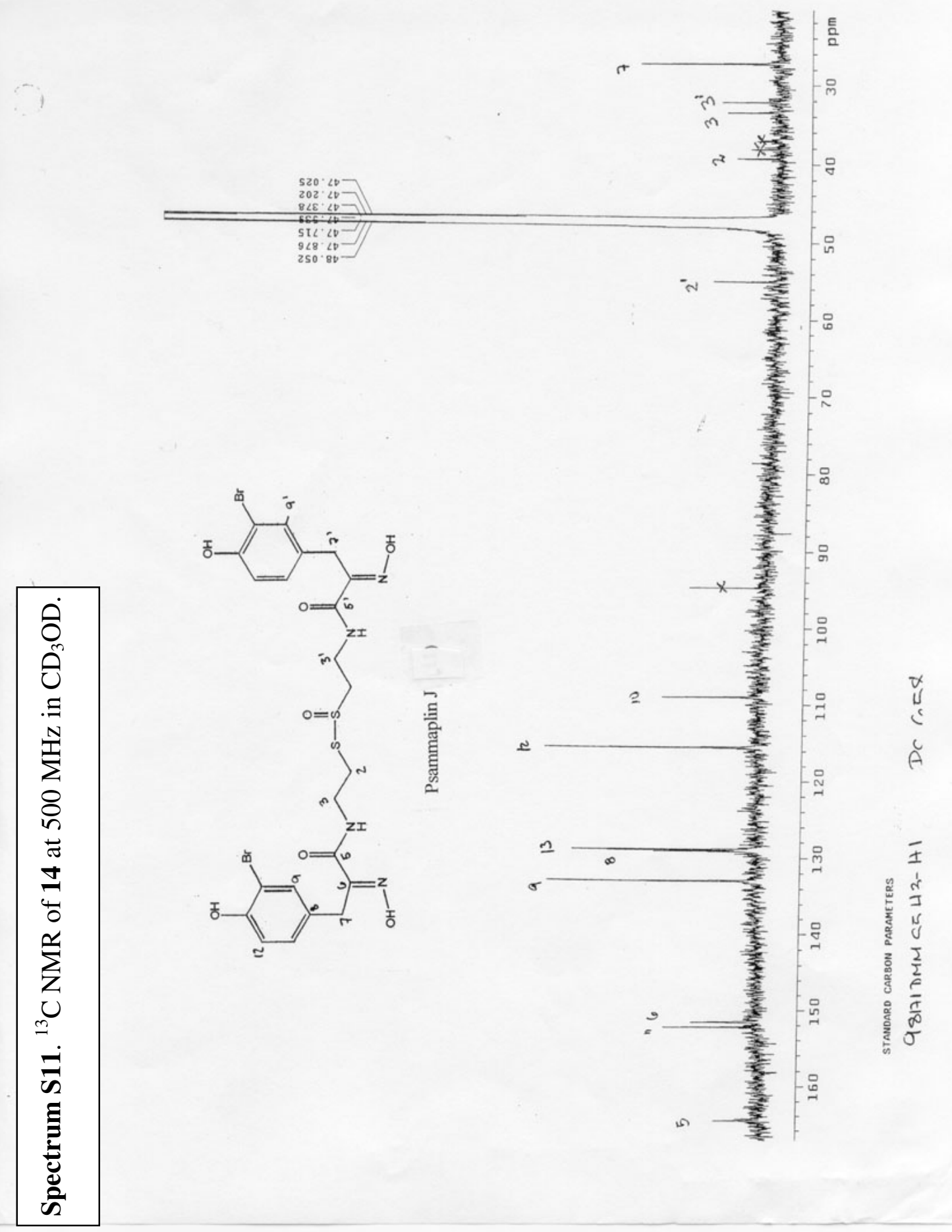



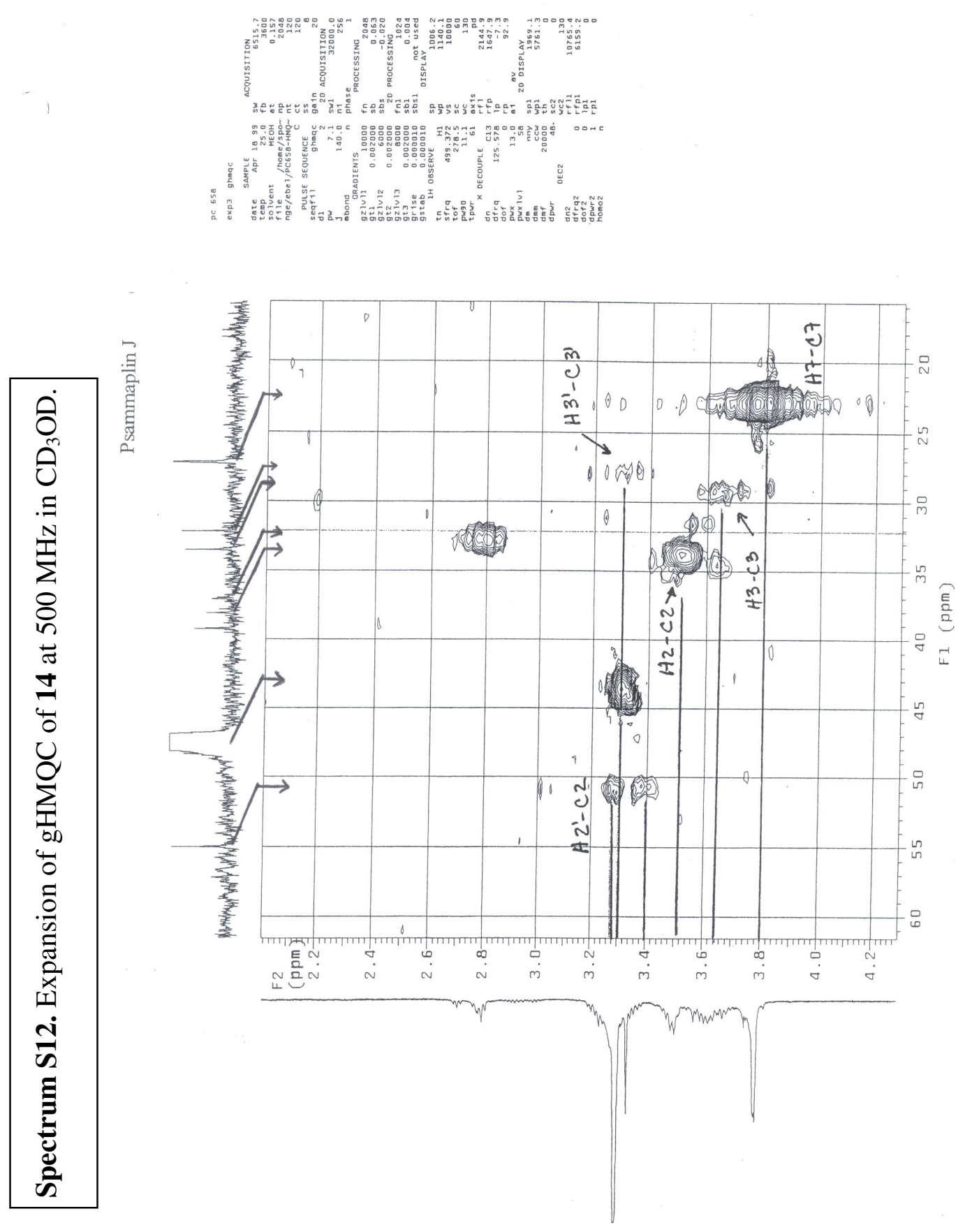